\title{
Life cycle of Armadillidium tunisiense from the Chambi National Park (Kasserine, Tunisia)
}

\author{
Mouna Khila ${ }^{1}$ and Mohamed Sghaier Achouri ${ }^{1}$ \\ ${ }^{1}$ University of Tunis El Manar
}

May 8, 2020

\begin{abstract}
1. Data on reproductive features of temperate terrestrial isopods species is well-known, for some species this knowledge is still incipient. Armadillidium tunisiense is a newly discovered and endemic Tunisian with an only recent study concerning its breeding patterns. 2. Seen the interspecific and intraspecific variations due to local variations in environmental conditions. We decided to describe the main characteristics of A. tunisiense's life cycle from the Chambi mountain, the highest point in Tunisia, by determining the population structure; the reproduction dynamics, the sex ratio and fertility. 3. The breeding patterns and the reproductive cycle of A. tunisiense were studied on 2908 individuals collected on regular bias from July 2009 to July 2011 from the Chambi mountain. Our specimens were divided into six categories. Where females were followed from the day of collection until their death. An in-depth study of a well-defined number (35 specimens) of reproductive females were desiccated to define the fertility by counting the eggs contained in the marsupium. 4. We found that A. tunisiense from the Chambi mountain is a semelparous species with a seasonal reproductive pattern, characterized by a reproduction period followed by a sexual rest. Also, we could've confirmed the positive relationship between the sizes of ovigerous females and fertility. With 5 eggs recuperated in a $5.2 \mathrm{~mm}$ female while 33 eggs were encountered in an $8 \mathrm{~mm}$ female. As well as for the sex ratio which characterized by fluctuation (0.49-1.12), but mainly in favor of females over that of males. 5 . The combined results of the previous study and ours maintain on the role of environmental conditions that interfere to explain the interspecific variations were observed for the launch and the duration of the reproduction period. Thus, altitude might confirm the intraspecific variations between both studied populations of A. tunisiense.
\end{abstract}

\section{Hosted file}

Main_text.docx available at https://authorea.com/users/319713/articles/449423-life-cycle-ofarmadillidium-tunisiense-from-the-chambi-national-park-kasserine-tunisia 